\title{
Investigation of Plantago ovata Husk as Pharmaceutical Excipient for Solid Dosage Form (Orodispersible Tablets)
}

\author{
Sarmad Abbas, ${ }^{1}$ Mehrin Sherazi, ${ }^{1}$ Amjad Khan, ${ }^{2}$ Hamad S. Alyami, ${ }^{3}$ Muhammad Latif, \\ Zia-Ur-Rahman Qureshi, ${ }^{5}$ Majeedullah, ${ }^{2}$ and Muhammad Hassham Hassan Bin Asad ${ }^{6,7}$ \\ ${ }^{1}$ Department of Pharmacy, Abasyn University, Peshawar, Pakistan \\ ${ }^{2}$ Department of Pharmacy, Kohat University of Science and Technology (KUST), Kohat, Pakistan \\ ${ }^{3}$ Department of Pharmaceutics, Najran University, Najran, Saudi Arabia \\ ${ }^{4}$ Department of Zoology, Division of Science and Technology, University of Education Lahore (Multan Campus), Pakistan \\ ${ }^{5}$ Department of Pharmacy, SBK Women University, Quetta, Balochistan, Pakistan \\ ${ }^{6}$ Department of Pharmacy, COMSATS University Islamabad (Abbottabad Campus), 22060, Pakistan \\ ${ }^{7}$ Institute of Fundamental Medicine and Biology, Department of Genetics, Kazan Federal University, Kazan, Russia
}

Correspondence should be addressed to Muhammad Hassham Hassan Bin Asad; hasshamasad@yahoo.com

Received 9 January 2021; Accepted 8 June 2021; Published 15 June 2021

Academic Editor: Ali Nokhodchi

Copyright (C) 2021 Sarmad Abbas et al. This is an open access article distributed under the Creative Commons Attribution License, which permits unrestricted use, distribution, and reproduction in any medium, provided the original work is properly cited.

\begin{abstract}
The objective of the study was to investigate the suitability of the Plantago ovata (PO) husk as a pharmaceutical excipient. Various phytoconstituents of the husk were determined according to the standard test procedures. The Plantago ovata husk was evaluated for various pharmaceutical parameters related to flow, swelling index, and compressibility index. Orodispersible tablets (ODTs) were prepared, containing different concentrations $(2.5,3,5,7.5,10$, and $15 \% w / w)$ of the Plantago ovata husk. Before compression, all the formulations were evaluated for their flow. Compressed ODTs were evaluated for physical characteristics (physical appearance, weight and weight variation, thickness, and moisture content), mechanical strength (crushing strength, specific crushing strength, tensile strength, and friability), disintegration behavior (disintegration time and oral disintegration time), drug content, and in vitro drug release. Phytochemical evaluation of the Plantago ovata husk confirmed the presence of various phytoconstituents like alkaloids, tannins, glycosides, saponins, flavonoids, and phenols. SEM photograph of the Plantago ovata husk showed that it has a fibrous structure, with a porous and rough surface. The Plantago ovata husk had a high swelling index $(380 \%)$ which decreased by pulverization (310\%). Precompression evaluation of the powder blend for all the formulations of ODTs showed good flow properties, indicating that the Plantago ovata husk improved the rheological characteristics of the powder blend. Compressed ODTs had good mechanical strength, and their friability was within the official limits $(<1 \%)$. Best disintegration was observed with formulation F-6 containing $10 \% \mathrm{w} / \mathrm{w}$ of the Plantago ovata husk. It is concluded that the Plantago ovata husk can be used as a disintegrant in the formulation of ODTs.
\end{abstract}

\section{Introduction}

Plantago ovata (PO) belongs to the genus Plantago, and with regard to its 200 known species, 10 species are found in the subcontinent. It is cultivated during November to April [1]. It is an herb and is $30-45 \mathrm{~cm}$, with $7.5-20 \mathrm{~cm}$ long and 0.6 $\mathrm{cm}$ broad leaves [2]. It has $1.2-4 \mathrm{~cm}$ spikes which are 0.5 $\mathrm{cm}$ broad and bearing 45-69 flowers [3]. Fruits are ellipsoid capsules $8 \mathrm{~mm}$ long, glabrous, and obtuse, and seeds are ovoid-oblong, smooth, boat shaped, and rosy-white convex on one side and concave on another side. The husk is obtained by milling the seed, with a total recovery of 25$26 \%$ [2]. The husk consists of fibrous insoluble fibers (34\%) and soluble fibers (66\%). Its mucilage contains up to $85 \%$ of different carbohydrates like arabinose, xylose, and galacturonic acid [4]; 0.94\% proteins (albumin, globulin, and prolamin); and $4.07 \%$ ash [5]. Traditionally, it is used as an antidiarrheal, laxative [6], antidiabetic, and antihyperlipidemic [7]. The husks of the PO Forsk seed are being used as a dietary fiber supplement to regulate large bowel 
functions, and in recent times, it has shown prominent blood cholesterol-lowering effects. Some of the pharmaceutical applications of PO have been reported. The husk shows negative thixotropy on dispersion in water; however, if heated to $60^{\circ} \mathrm{C}$, it is transformed to a thixotropic gel with bulges and spurs. The mucilage has emulsification properties [8] and is a good suspension agent [9]. The $2 \% \mathrm{w} / v$ mucilage (seedhusk powder) in cool water matches well, while $1.5 \% \mathrm{w} / \mathrm{v}$ mucilage in warm water is better than $10 \% w / v$ starch mucilage in terms of binding properties [10]. It is comparable to methyl cellulose and is much better than both sodium alginate and sodium carboxymethyl cellulose in suspending properties [9]. The carboxymethyl derivative of the PO husk is a fibrous mass, lighter in odor, and mucilaginous in taste. It swells well in water, making gummy mucilage of $\mathrm{pH} 6.7$ and swelling factor 90. It is better than the integral husk in viscosity [11], spreadability, film creating features, and smooth texture [12]. The husk hazy aqueous extract is an exceptional thickening agent. The husk of PO seeds has good gelling and gliding properties. Furthermore, it absorbs water and swells to a larger extent. It is bulky in nature, with a low density, and is expected to increase flow characteristics of other powder materials. These characteristics of the PO husk make the basis for its proper investigation as a pharmaceutical excipient for solid dosage form (tablet).

A number of disintegrants are available with varying degrees of disintegration action. The main problem with available disintegrants is their effect on the mechanical strength of tablets $[13,14]$. A higher concentration of disintegrants makes tablets prone to friability, so they should be used in lower recommended concentrations. Furthermore, higher concentration in orodispersible tablets (ODTs) can cause grittiness in the oral cavity [15]. There is a need for cost effective and safe disintegrants which can be used in larger quantities, without compromising the mechanical strength of tablets. Natural products are preferred due to their nontoxic, nonirritant, cost effectiveness, and local accessibility. In this study, domperidone was used as the model drug in the preparation of ODTs for determination of the suitability of the PO husk as a disintegrant. Domperidone is an antidopaminergic drug, used for the treatment of gastroesophageal reflux disorder (GERD), vomiting, and delayed gastric emptying [16]. It has poor water solubility, is a tasteless drug, and has a dose strength of $10 \mathrm{mg} /$ tablet.

Materials of natural origin have been used in pharmaceutical preparations at various stages because of their safe nature, easy availability, and cost effectiveness. Our main objective was to investigate suitability of the PO husk as a pharmaceutical excipient for solid dosage form. In the present study, physicochemical characteristics of the PO husk were determined, and various formulations of ODTs of domperidone were developed, using the PO husk as the disintegrant. The obtained results were compared with commonly used pharmaceutical ingredients.

\section{Material and Methods}

2.1. Material. Domperidone (Ningbo Sansheng Pharmaceutical Company, China; purity $99.83 \%$ with respect to BP stan- dard) was gifted by Nenza Pharmaceuticals, Peshawar, Pakistan. Other materials like the PO husk (Muhammad Hashmi Husks, Karachi, Pakistan), sodium starch glycolate (Primojel; CHP Carbohydrates, Pirna, Germany), magnesium stearate (Coin Powder International Company Ltd., Taiwan), Tablettose-80 (BDH Chemical Limited, Poole, England), microcrystalline cellulose (Dr. Reddy's Laboratories, India), and flavour (Fab Flavours and Fragrances Pvt. Ltd., India) were acquired locally in Peshawar, Pakistan. All these ingredients were of pharmaceutical quality and were utilized without any processing.

2.2. Instruments and Equipment. Instruments used for evaluation of physicochemical characteristics of the PO husk and preparation of ODTs included sieve shaker (Endicott Ltd., England), laboratory-scale double cone mixer (Morgan Machinery Ltd., Pakistan), rotary tablet compression machine ZP-19 (STC, China), rotary granulator (STC, China), digital balance (LIBROR AEG-120, Shimadzu, Japan), tablet disintegration apparatus (Pharma Test, Germany), dissolution testing apparatus (Pharma Test, Germany), digital tablet hardness and thickness tester (Pharma Test, Germany), double drum friabilator (Faisal Engineering, Pakistan), and UV-visible spectrophotometer (Shimadzu, Japan).

\subsection{Pharmaceutical Evaluation of PO Husk}

2.3.1. Density. The husk bulk density was calculated as per the official USP method using a graduated cylinder [17]. In the graduated cylinder, the volume of the weighed quantity of powder was measured, and density was estimated by the equation $D=m / v$ (equation (1)), where $D$ is the density of the powder $(\mathrm{g} / \mathrm{mL}), m$ is the weight of the powder, and $v$ is the volume of the powder $(\mathrm{mL})$. Tapped density of the PO husk was obtained by the USP method, i.e., by the tapping of powder in a graduated cylinder and noting the volume reduction [17]. Tapping was done manually. The final volume of the husk was taken as the tapped volume and was used for the calculation of the tapped density. All measurements were triplicated and the values presented as mean \pm standard deviation $(n=3)$.

2.3.2. Carr's Index. Carr's index was estimated based on the tapped and bulk densities of the PO husk [18], by the following equation: $\mathrm{C} . \mathrm{I}=(\mathrm{Dc}-\mathrm{Da} / \mathrm{Dc}) \times 100 \quad$ (equation $(2))$, where C.I is Carr's index of the powder (\%), Dc is the tapped density of the powder $(\mathrm{g} / \mathrm{mL})$, and $D a$ is the bulk density of the powder $(\mathrm{g} / \mathrm{mL})$.

2.3.3. Hausner Ratio. The Hausner ratio was also assessed from the bulk and tapped density values of the PO husk [18] by the following equation: $\mathrm{Hr}=\mathrm{Dc} / \mathrm{Da}$ (equation (3)), where $\mathrm{Hr}$ is the Hausner ratio of the powder, $\mathrm{Dc}$ is the powder tapped density $(\mathrm{g} / \mathrm{mL})$, and $D a$ is the powder bulk density $(\mathrm{g} / \mathrm{mL})$.

2.3.4. Angle of Repose (AOR). AOR was obtained as per the USP funnel method [18]. The PO husk was allowed to flow from a glass funnel fitted at a specified height, and AOR 
was calculated on the basis of the height and radius of the heap; $\propto=\tan ^{-1}(H / r)$ (equation (4)), where $\alpha$ is the AOR of the powder $\left(^{\circ}\right), H$ is the cone height shaped by the powder $(\mathrm{cm})$, and $r$ is the cone base radius shaped by the powder $(\mathrm{cm})$.

2.3.5. Swelling Index. The swelling index of the PO husk was determined according to USP [18]. The weighed amount of the husk was taken in a graduated cylinder and its volume $\left(V_{1}\right)$ was measured. Sufficient quantity of purified water was added to the graduated cylinder containing the PO husk and kept undisturbed for $3 \mathrm{~h}$. Volume of the swollen PO husk was noted $\left(V_{2}\right)$, and the swelling index was calculated by the following equation: Swelling index $=\left(V_{2}-V_{1}\right) / V_{1} \times 100$ (equation (5)), where $V_{1}$ is the volume occupied by the dry husk and $V_{2}$ is the volume of the swollen husk. The swelling index was determined in triplicate, and the mean and standard deviation were calculated.

2.3.6. Interparticle Porosity. Bulk and tapped density values were used for estimation of the interparticle porosity [18] by the following equation: $\mathrm{Ie}=(\mathrm{Dc}-\mathrm{Da}) / \mathrm{Dc} \times \mathrm{Da}$ (equation (6)), where $I e$ is the interparticle porosity, $D c$ is the tapped density $(\mathrm{g} / \mathrm{mL})$, and $D a$ is the bulk density $(\mathrm{g} / \mathrm{mL})$.

2.3.7. Loss on Drying (LOD). LOD was obtained gravimetrically according to USP [18], using a halogen moisture analyzer. Approximately $1 \mathrm{~g}$ of powder was taken on an analyzer pan and heated for a stated time $(5 \mathrm{~min})$ at $100^{\circ} \mathrm{C}$, and the percentage weight loss was calculated. LOD experiments were triplicated, and values presented as mean $\pm S D(n=3)$.

2.3.8. Compressibility. Compressibility of the PO husk was assessed on the basis of the cohesion index. The cohesion index is the crushing strength of the powder compressed in an eccentric press, under maximum pressure without capping and lamination [19]. The mean crushing strength was calculated for ten compactions $(n=10)$, indicating cohesion index of the PO husk.

2.4. Phytochemical Evaluation of PO Husk. The PO husk was studied for the presence of various classes of compounds, according to the standard protocols as follows.

2.4.1. Test for Carbohydrates. The PO husk was soaked in purified water $(5 \mathrm{~mL})$ for $5 \mathrm{~min}$ and filtered. Alcoholic $\alpha$ naphthol solution ( 3 drops) was added to the filtrate and taken in a test tube, and the junction was observed. The presence of carbohydrates was confirmed by the appearance of a violet ring at the junction.

2.4.2. Test for Alkaloids. The presence of alkaloids in the PO husk was confirmed by Mayer's test. The PO husk (2.5 g) was extracted with methanol and $\mathrm{HCl}(2 \mathrm{~N})$ was added. The mixture was heated at $40 \pm 3^{\circ} \mathrm{C}$, cooled, and filtered. This filtrate was reacted with Mayer's reagent (potassium mercuric iodide), and the precipitate growth was checked. The appearance of yellow colored precipitate confirmed the presence of alkaloids.
2.4.3. Test for Saponins. The PO husk was soaked in boiling water in a test tube. After a specified time, the mixture was cooled and vigorously shaken till froth formation. Afterward, the test tube was placed on a stand for $\sim 15 \mathrm{~min}$, and the results were noted. Strongly positive $(+++)$ meant more than $5 \mathrm{~cm}$ froth, $(++)$ meant more than $2 \mathrm{~cm}$ froth, $(+)$ meant $<1$ $\mathrm{cm}$ froth, and (-) represented no froth.

2.4.4. Test for Phenols. The PO husk was soaked in water and filtered. The filtrate was reacted with ferric chloride solution (3-4 drops), and the formation of precipitate was observed. The appearance of bluish black colored precipitate indicated the presence of phenol.

2.4.5. Test for Glycosides. The presence of glycosides in the PO husk was evaluated by the Keller-Kiliani test [2]. Extract $(2 \mathrm{~mL})$ was reacted with glacial acetic acid $(1 \mathrm{~mL})$ and $\mathrm{FeCl}_{3}$ (1-2 drops), then treated with concentrated $\mathrm{H}_{2} \mathrm{SO}_{4}(1 \mathrm{~mL})$. Development of green blue color indicated the presence of cardiac glycosides and vice versa.

2.5. Preparation of Orodispersible Tablets Using PO Husk as Disintegrant. A direct compression process was used for the preparation of ODTs using domperidone as the model drug. Various formulations of ODTs were developed using different concentrations of the PO husk as disintegrant as shown in Table 1. All the ingredients were weighed, sifted, and mixed for $15 \mathrm{~min}$ in a lab scale double cone blender at 25 $\mathrm{rpm}$. This powder mixture was compressed by a ZP-19 rotary compression machine (STC, China) with $10 \mathrm{~mm}$ round, shallow concave punch fitting. A minimum of 500 tablets were prepared for all formulations.

2.6. Precompression Evaluation. Prior to compression, the powder blend of all the formulations was evaluated for various parameters related to flow-like bulk density, tapped density, Carr's index, Hausner ratio, angle of repose, and interparticle porosity, as per Section 2.3.

2.7. Postcompression Evaluation. Compressed ODTs were extensively evaluated for various official and unofficial parameters, as follows.

2.7.1. Physical Parameters of Tablets. Experimental tablet weight variation from all formulations was determined by weighing 20 tablets individually [20] on a digital balance (Precisa, Switzerland). While the thickness of ten randomly chosen tablets was tested by a digital tester (Pharma Test, Germany), the mean and standard deviation were calculated. Domperidone quantity of the ODTs was estimated as per the official British Pharmacopoeia method [18]. Absorbance of the test and standard solutions was noted at $384 \mathrm{~nm}$ using a double beam UV-visible spectrophotometer (PerkinElmer, USA), and drug percentage was determined. A reported method was used to calculate tablet wetting time using filter paper [21]. A filter paper folded twice was taken in a Petri dish having $5 \mathrm{~mL}$ of purified water; the tablet was then put on the paper and the time for thorough wetting was noted.

2.7.2. Mechanical Properties of ODTs. The mechanical strength of ODTs was measured based on tablet crushing 
TABLE 1: Composition of various formulations of orodispersible tablets of domperidone containing PO husk as disintegrant, prepared by direct compression technique.

\begin{tabular}{lccccccc}
\hline Ingredients & F-1 (control) & F-2 & F-3 & F-4 & F-5 & F-6 & F-7 \\
\hline Domperidone & 6.67 & 6.67 & 6.67 & 6.67 & 6.67 & 6.67 & 6.67 \\
Flavor (orange) & 0.50 & 0.50 & 0.50 & 0.50 & 0.50 & 0.50 & 0.50 \\
Aspartame (sweetener) & 3.00 & 3.00 & 3.00 & 3.00 & 3.00 & 3.00 & 3.00 \\
Primojel & 3.00 & - & - & - & 2.50 & - & - \\
Plantago ovata husk & - & 3.00 & 5.00 & 7.50 & 2.50 & 10.00 & 15.00 \\
Microcrystalline cellulose (Ph102) & 50.00 & 50.00 & 50.00 & 50.00 & 50.00 & 50.00 & 50.00 \\
Tablettose-80 & 35.33 & 35.33 & 33.33 & 30.83 & 33.33 & 28.33 & 23.33 \\
Magnesium stearate & 1.50 & 1.50 & 1.50 & 1.50 & 1.50 & 1.50 & 1.50 \\
\hline
\end{tabular}

Note: quantities are given in $\%(w / w)$.

TABLE 2: Pharmaceutical characterization of PO husk.

\begin{tabular}{lc}
\hline Parameter (unit) & Result \\
\hline Bulk density (g/mL) & $0.249 \pm 0.004(n=3)$ \\
Tapped density $(\mathrm{g} / \mathrm{mL})$ & $0.282 \pm 0.001(n=3)$ \\
Carr's index & 12.41 \\
Hausner ratio & 1.13 \\
Angle of repose $\left(^{\circ}\right)$ & 0.00 \\
Flowability (sec) & 0.00 \\
Swelling index (unprocessed) $(\%)$ & $380 \pm 5.29(n=3)$ \\
Swelling index (powdered) $(\%)$ & $310 \pm 3.64(n=3)$ \\
Interparticle porosity & 0.499 \\
Loss on drying (\%) & $1.87 \pm 0.13(n=3)$ \\
Compressibility & 0.00 \\
\hline
\end{tabular}

Note: results are presented as mean $\pm \mathrm{SD}(n=3)$; time taken by $100 \mathrm{~g}$ husk to flow through an orifice; parameter has no unit because it is the ratio between two parameters with same units; powder was unable to flow and hence the parameter was unable to be determined.

strength, specific crushing strength, tensile strength, and friability. For every formulation, the crushing strength was calculated on ten randomly chosen tablets $(n=10)$, by digital hardness and thickness tester (Pharma Test, Germany). The mean crushing strength and thickness values were then utilized in the estimation of tablet tensile strength and specific crushing [18] using equations (7) and (8), respectively, viz., $T=2 F / \pi D H$ (equation (7)) and $\tau=$ $F / H D$ (equation (8)), where $T$ is the tensile strength of tablets $\left(\mathrm{N} / \mathrm{mm}^{2}\right), \tau$ is the specific hardness of the tablet $\left(\mathrm{N} / \mathrm{mm}^{2}\right), F$ is the crushing strength of the tablet $(\mathrm{N}), H$ is the thickness of the tablet $(\mathrm{mm}), D$ is the diameter of the tablet $(\mathrm{mm})$, and $\tau$ is the proportionality constant having value of 3.143. The formulation tablet friability was estimated in accordance with official compendia [18], by a single drum friabilator (Faisal Engineering, Pakistan).

2.7.3. Disintegration Behavior of ODTs. Disintegration behavior of ODTs was estimated on the basis of disintegration time and oral disintegration time. Tablet disintegration time (D.T) was carried out in distilled water at $37 \pm 2^{\circ} \mathrm{C}$ as per official USP [17]. The mean of the disintegration time of six tablets was taken as the disintegration time of the tablet.

Oral D.T of ODTs was assessed by a panel of six healthy male volunteers. Prior to the test, every subject was asked to rinse his oral cavity with purified water $(200 \mathrm{~mL})$. One tablet was placed on the tongue of the volunteer, and a stopwatch was started directly. All subjects were taught to cause a tumbling action by moving the tablet slowly against the upper portion of the oral cavity and evading side-to-side tumbling or biting. The time taken for complete disintegration of the tablet was noted. Mean of six determinations $(n=6)$ was taken as the oral disintegration time. At the end of the test, each volunteer was asked about the grittiness felt in the oral cavity and to rank the taste of the tablet as per the following scale: 0: tasteless, 1: pleasant tasting, 2: sweet, and 3: strongly sweet. As human volunteers were involved in the determination of the oral disintegration time, the study was permitted by the Committee for Ethics in Research at the Department of Pharmacy, Abasyn University Peshawar, and written consent forms were signed by all the participants.

2.7.4. In Vitro Drug Release. The dissolution rate of domperidone was estimated as per the official British Pharmacopoeia [20] with a dissolution medium which used $0.1 \mathrm{~N}$ hydrochloric acid $(900 \mathrm{~mL})$ held at $37 \pm 2^{\circ} \mathrm{C}$ in a USP Dissolution Apparatus-II (paddle method). The operation speed of the paddle was set at $50 \mathrm{rpm}$ [20]. At defined time intervals, a sample $(5 \mathrm{~mL})$ was taken and fresh medium was added $(0,5$ $10,15,30,45$, and $60 \mathrm{~min}$ ) and filtered. Total drug release was estimated by measuring the UV absorbance of the sample at $284 \mathrm{~nm}$ using a double beam UV spectrophotometer (Shimadzu, Japa3).

\section{Results}

The swelling index of the PO husk was very high (380\%) indicating its good water absorbing capacity. Pulverization of the husk into fine powder has an adverse effect on the swelling index. The swelling index of the powdered PO husk was $310 \%$, which was very low as compared with unpulverized. The PO husk has a low density with poor compressibility, as shown in Table 2. The PO husk was unable to flow, and its angle of repose cannot be determined. Other parameters 
TABle 3: Phytochemical constituents of PO husk.

\begin{tabular}{lcc}
\hline Test for presence of & Observations & Result \\
\hline Alkaloids & Colored precipitate present with these reagents & Alkaloids present \\
Tannins & Dark green solution/blue-black precipitate & Tannins present \\
Saponins & Persistent froth & Saponins present \\
Flavonoids & Yellow solution that turns to colorless & Flavonoids present \\
Glycosides & Reddish brown layer formed at interface & Glycosides present \\
Phenols & Formation of green precipitates indicate phenols & Phenols present \\
\hline
\end{tabular}

Table 4: Precompression evaluation of powder blend containing PO husk in different concentrations.

\begin{tabular}{|c|c|c|c|c|c|c|c|}
\hline Characteristics (unit) & F-1 (control) & $\mathrm{F}-2$ & F-3 & F-4 & F-5 & F-6 & F-7 \\
\hline Bulk volume (mL) & 25.00 & 25.00 & 25.00 & 25.00 & 25.00 & 25.00 & 25.00 \\
\hline Tapped volume (mL) & 23.00 & 22.00 & 23.50 & 23.00 & 23.00 & 20.00 & 18.00 \\
\hline Bulk density $(\mathrm{g} / \mathrm{mL})$ & 0.48 & 0.44 & 0.43 & 0.47 & 0.48 & 0.39 & 0.38 \\
\hline Tapped density $(\mathrm{g} / \mathrm{mL})$ & 0.52 & 0.47 & 0.45 & 0.51 & 0.50 & 0.41 & 0.40 \\
\hline Hausner ratio* & 1.11 & 1.06 & 1.06 & 1.09 & 1.05 & 1.05 & 1.07 \\
\hline Carr's index* & 7.85 & 5.77 & 5.74 & 8.06 & 4.59 & 4.62 & 6.45 \\
\hline Angle of repose $\left({ }^{\circ}\right)$ & 36.16 & 27.95 & 25.42 & 30.61 & 30.72 & 23.02 & 22.01 \\
\hline
\end{tabular}

${ }^{*}$ The given parameters have no unit as these are ratios between parameters with same units.

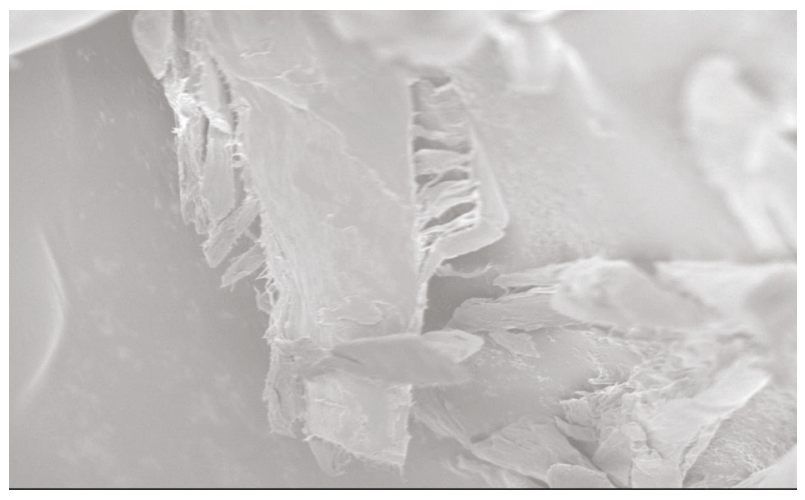

FIGURE 1: SEM photograph of PO husk fibers.

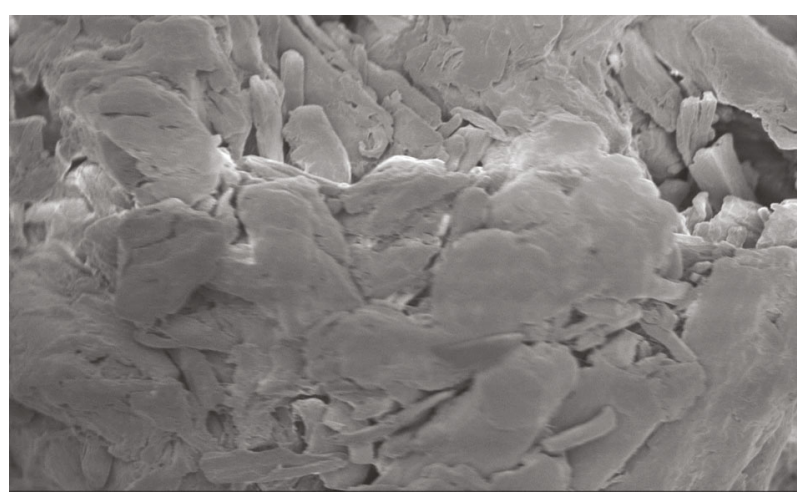

FIGURE 2: SEM photograph showing closer look at the surface of PO husk. related to flow also showed poor results. Phytochemical evaluation of the PO husk was performed according to the standard protocols, and the presence of different phytochemicals was confirmed, as shown in Table 3. Prior to compression, the powder blend was evaluated for various parameters like bulk density, tapped density, Hausner ratio, Carr's index, and angle of repose, according to the official method (USP) [18]. The powder blend for all the formulations had better flow as evidenced from the results presented in Table 4. Figure 1 shows a SEM photograph of the PO husk, indicating its fibrous nature. A closer look of the surface showed that it was very rough, providing a larger surface area for water absorption, as shown in Figure 2. Figure 3 shows the IR spectra of pure domperidone and the spectra of a physical mixture of the PO husk, domperidone, and other ingredients (as per Table 1) in 1:1 by weight, after subjecting to stress conditions $\left(40 \pm 2{ }^{\circ} \mathrm{C}\right.$ and $75 \pm 5 \%$ relative humidity) for 15 days. Figure 4 shows the results of the XRD analysis of a mixture of PO husk and excipients used in the formulation of ODTs. The wetting time for all the formulations was lower than that of the control formulation (F-1) which did not contain the PO husk. Increase in the concentration of the PO husk resulted in decreased wetting, as shown in Table 5. A smaller wetting time shows good absorption and distribution of water by ODTs, which was because of the hydrophilic nature of the PO husk. A direct correlation was observed between the quantity of the husk and the decrease in the wetting time, i.e., the increase in quantity of the PO husk decreased the wetting time.

ODTs disintegrate in the oral cavity, and all the ingredients (API+excipients) are in direct contact with oral mucosa and taste buds. It makes evaluation of the mouth feel with ODTs a mandatory test. Bad taste and grittiness are 


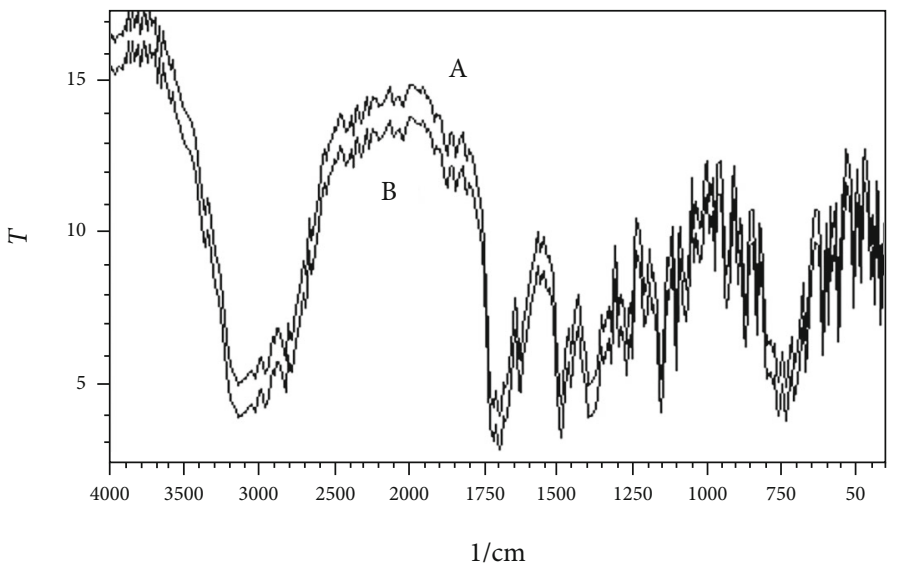

FIGURE 3: IR spectra of domperidone (A) and mixture of domperidone, PO husk, and other excipients after subjecting to stress conditions $\left(40 \pm 2^{\circ} \mathrm{C}\right.$ and $75 \pm 5 \%$ relative humidity) for 15 days.

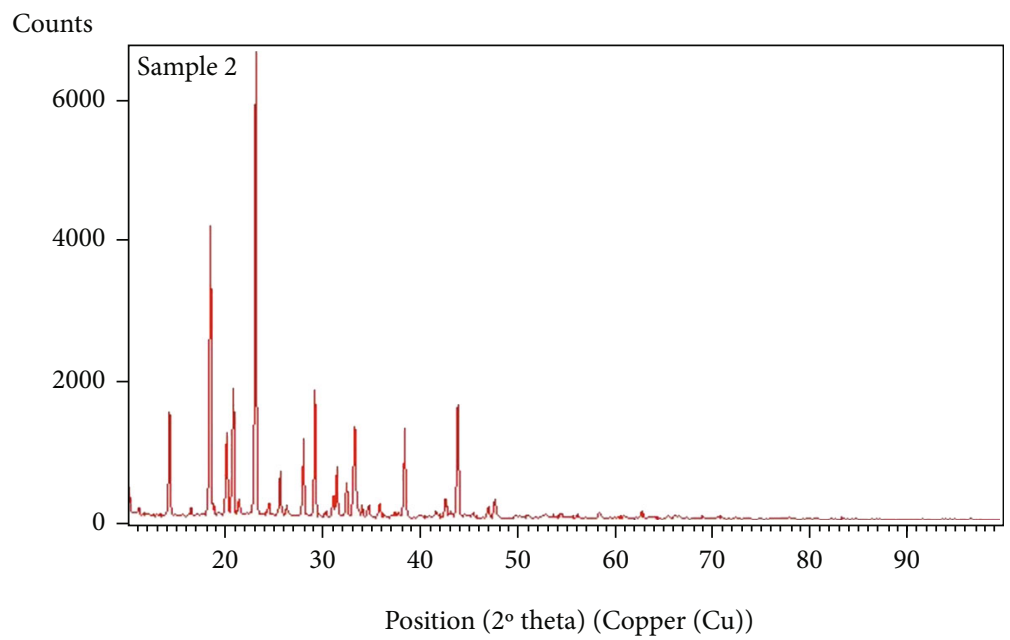

FIGURE 4: Results of XRD analysis of mixture of PO husk with other ingredients used in formulation of ODTs.

TABLe 5: Physical parameters of ODTs of domperidone prepared by direct compression technique.

\begin{tabular}{lccccc}
\hline Formulation code & Weight variation $(\%)$ & Tablet thickness $(\mathrm{mm})$ & Tablet diameter $(\mathrm{mm})$ & Wetting time $(\mathrm{sec})$ & Drug content $(\%)$ \\
\hline F-1 (control) & \pm 2.19 & $3.91 \pm 0.81$ & $7.46 \pm 0.08$ & $185.66 \pm 1.624$ & $100.08 \pm 0.73$ \\
F-2 & \pm 1.09 & $3.9 \pm 0.28$ & $7.45 \pm 0.04$ & $71.33 \pm 1.307$ & $99.86 \pm 0.49$ \\
F-3 & \pm 2.21 & $3.98 \pm 0.52$ & $7.48 \pm 0.07$ & $59.66 \pm 1.753$ & $99.94 \pm 1.19$ \\
F-4 & \pm 3.30 & $3.88 \pm 0.92$ & $7.51 \pm 0.02$ & $42.33 \pm 1.945$ & $100.24 \pm 0.28$ \\
F-5 & \pm 2.23 & $3.92 \pm 0.40$ & $7.52 \pm 0.06$ & $58.33 \pm 1.292$ & $100.01 \pm 0.93$ \\
F-6 & \pm 3.67 & $3.90 \pm 0.64$ & $7.45 \pm 0.01$ & $59.66 \pm 1.922$ & $99.68 \pm 0.71$ \\
F-7 & \pm 2.38 & $3.92 \pm 0.61$ & $7.58 \pm 0.02$ & $42.30 \pm 1.809$ & $99.81 \pm 0.79$ \\
\hline
\end{tabular}

commonly observed upon oral ingestion, and the bad (usually bitter) taste is due to API while grittiness is caused by the excipients. Domperidone is a tasteless drug, and the taste of ODTs further improved by inclusion of a sweetener (aspartame $3 \% w / w)$ and flavor $(0.5 \% w / w)$. The PO husk was expected to cause grittiness due to its high water absorbing capacity. Upon contact with saliva, it forms a thick gel and sticks to the oral mucosa, creating a very bad sensation.
So, placebo (drug free) ODTs containing different concentrations of the PO husk (within the range of $0.5-10 \% w / w$ ) were prepared and evaluated by a panel of healthy human volunteers $(n=6)$ for taste and mouth feel. Grittiness of the tablets was ranked from 0 to 3 , with 0 as no grittiness. The highest quantity of the PO husk in placebo ODTs was $10 \% \mathrm{w} / \mathrm{w}$. It caused no grittiness at this level as shown in Table 6. Some grittiness was observed at the $10 \%$ 
TABLE 6: Level of grittiness caused by placebo (drug-free) ODTs containing different concentrations of PO husk.

\begin{tabular}{lccc}
\hline $\begin{array}{l}\text { Quantity of PO husk } \\
(\% w / w)\end{array}$ & $\begin{array}{c}\text { Quantity of sweetener } \\
+ \text { flavor }(\% w / w)\end{array}$ & $\begin{array}{c}\text { Number of } \\
\text { volunteers } \\
\text { rated ODTs } \\
\text { as }\end{array}$ \\
\hline 1.00 & $3.00+0.50$ & $6-1 \quad 2 \quad 3$ \\
2.50 & $3.00+0.50$ & $6--$ & - \\
5.00 & $3.00+0.50$ & $6--$ & - \\
7.50 & $3.00+0.50$ & $-51-$ & - \\
10.00 & $3.00+0.50$ & -2 & 4 \\
\hline
\end{tabular}

0: no grittiness; 1: acceptable; 2: mild grittiness; 3: grittiness.

TABLE 7: Mechanical strength of ODTs containing different concentrations of PO husk, prepared by direct compression.

\begin{tabular}{lcccc}
\hline $\begin{array}{l}\text { Formulation } \\
\text { code }\end{array}$ & $\begin{array}{c}\text { Crushing } \\
\text { strength } \\
(\mathrm{kg})\end{array}$ & $\begin{array}{c}\text { Tensile } \\
\text { strength } \\
\left(\mathrm{kg} / \mathrm{mm}^{2}\right)\end{array}$ & $\begin{array}{c}\text { Specific } \\
\text { crushing } \\
\text { strength } \\
\left(\mathrm{kg} / \mathrm{mm}^{2}\right)\end{array}$ & $\begin{array}{c}\text { Friability } \\
(\%)\end{array}$ \\
\hline F-1 & $3.67 \pm 0.43$ & 0.080 & 0.125 & 0.74 \\
F-2 & $3.73 \pm 0.93$ & 0.081 & 0.128 & 0.24 \\
F-3 & $4.24 \pm 0.71$ & 0.090 & 0.142 & 0.71 \\
F-4 & $4.19 \pm 0.58$ & 0.087 & 0.137 & 0.72 \\
F-5 & $4.41 \pm 0.09$ & 0.095 & 0.149 & 0.24 \\
F-6 & $5.51 \pm 0.36$ & 0.120 & 0.189 & 0.49 \\
F-7 & $5.48 \pm 0.68$ & 0.117 & 0.184 & 0.24 \\
\hline
\end{tabular}

concentration as two volunteers reported mild grittiness. The rest of the volunteers declared the tablet free of grittiness. Mechanical strength of ODTs was assessed on the basis of their crushing strength, specific crushing strength, tensile strength, and friability, determined according to official compendia [20]. All the parameters were determined in accordance with USP. The crushing strength of ODTs was in the range of $3.67-5.59 \mathrm{~kg}$, indicating good crushing strength. Similarly, results of other parameters like tensile strength, specific crushing strength, and friability were observed, indicating good mechanical strength. Moreover, friability of all the formulations was within the acceptable range (not more than $0.8 \%$ ). It may be due to the fibrous nature of the PO husk which created bonding among the ingredients of ODTs (Table 7).

The disintegration time and oral disintegration time are the two major indicators for determining the disintegration behavior of ODTs. In the present study, the disintegration time was determined according to USP, using purified water as disintegration media at $37 \pm 2^{\circ} \mathrm{C}$. All the tablets had disintegration time within the official limits for ODTs (not more than $3 \mathrm{~min}$ ). The lowest disintegration time was observed with formulation F-6, containing 10\% PO husk. The PO husk rapidly absorbs water and swells to a large extent, causing tablet disintegration. Oral disintegration time was deter- mined by a panel of healthy male volunteers $(n=6)$. The British Pharmacopoeia [18] recommends $0.1 \mathrm{~N} \mathrm{HCl}(900$ $\mathrm{mL}$ ) as dissolution media, stirred with apparatus-II (peddle method) at $50 \mathrm{rpm}$, for dissolution testing of conventional tablets of domperidone. The dissolution rate of ODTs was determined using the same dissolution media and under the same experimental conditions. Complete (100\%) drug release was observed with all the formulations, irrespective of the amount of disintegrant. Furthermore, the strength of ODTs was $10 \mathrm{mg} /$ tablet, and it has good solubility in $0.1 \mathrm{~N}$ $\mathrm{HCl}$, so the dose-to-solubility ratio was high and the sink condition developed during dissolution testing.

\section{Discussion}

In the present study, the husk of PO seeds was evaluated for its suitability to be used as a pharmaceutical excipient for solid dosage form (tablet). The PO husk was evaluated for various pharmaceutical parameters like density, Hausner ratio, Carr's Index, angle of repose, solubility, loss on drying, and compressibility. Results showed that the PO husk was unable to flow, but it increased the flow of the powder blend significantly. The PO husk had a high swelling index, resulting in rapid disintegration of ODTs in a concentrationdependent manner. Furthermore, it had a positive effect on the mechanical strength of ODTs. The PO husk is water insoluble, but it absorbs a large quantity of water and swells up. To get better water absorption and subsequent swelling and disintegration, the PO husk should be used without pulverization. It has been reported that the PO husk mainly contains carbohydrates and glycosides [20], and results presented in Table 3 are in agreement with the reported literature. The direct compression technique was applied for the preparation of ODTs of domperidone, using the PO husk as a disintegrant in different concentrations. The PO husk has poor flow and compressibility, and its adverse effect on the powder blend was expected. Better compressibility and flow characteristics of Tablettose- 80 compensated for the poor flow of the PO husk. Furthermore, all the formulations containing the PO husk showed better flow than the control formulation (F-1) which may be because of the glidant effect of the husk due to its bulky and slippery fibrous nature.

The PO husk was found compatible with domperidone and other ingredients, used in the formulation of ODTs. All the characteristic peaks were present in both the spectra, and no shift was observed, indicating compatibility of the ingredients with each other. Compatibility of the PO husk with other ingredients of the formulation was further confirmed by its XRD analysis, as shown in Figure 4. ODTs of domperidone were prepared with $10 \mathrm{~mm}$ round, shallow concave punches. Compression weight of the tablets was $150 \mathrm{mg}$, and weight variation was in a narrow range, as shown in Table 5. Results of the weight variation showed that the flow of the powder blend was not affected by the PO husk. Physically, tablets from all the formulations had a smooth and shiny surface and were free of sticking and picking, indicating proper lubrication. Results showed that ODTs containing the PO husk as disintegrant will be free of grittiness. In concentrations below $10 \%$, the PO husk forms a paste- 


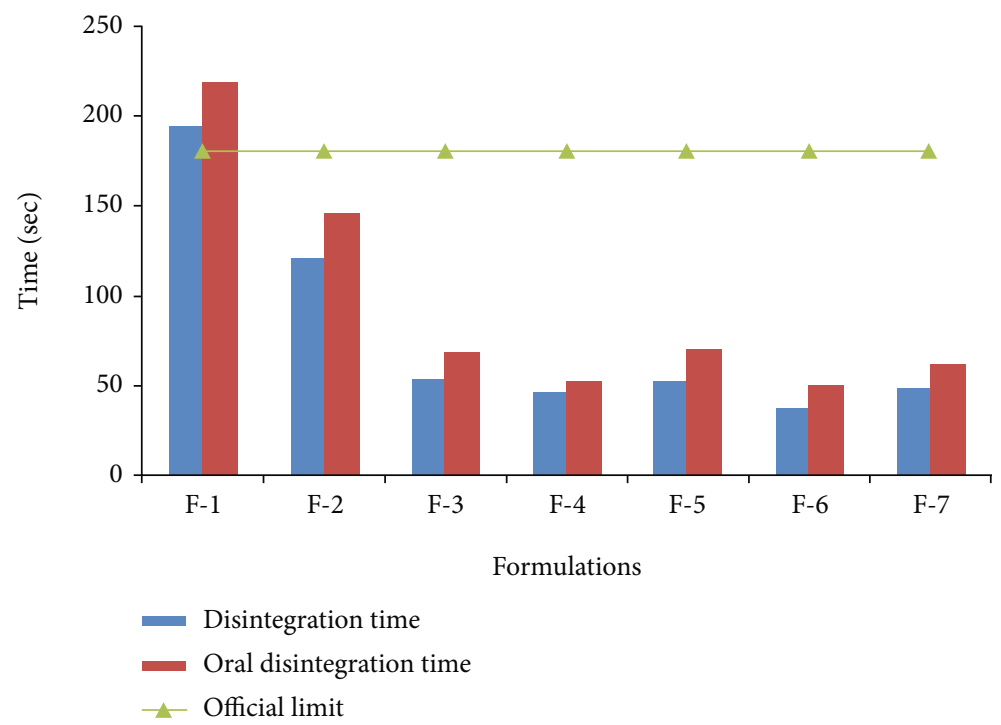

FIgURe 5: Disintegration time and oral disintegration time of ODTs containing PO husk.

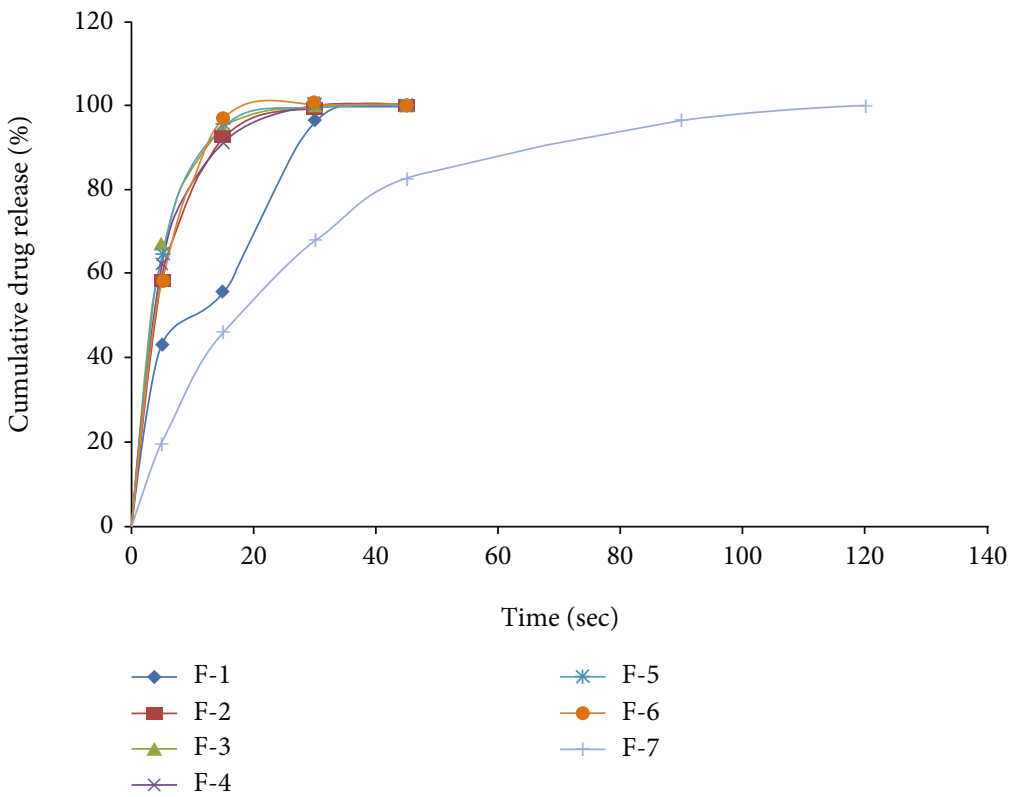

FIGURE 6: In vitro drug release of domperidone from ODTs containing PO husk as disintegrant. Dissolution rate was determined in $0.1 \mathrm{~N}$ HCl $(900 \mathrm{~mL})$, using USP apparatus-II (peddle) at $50 \mathrm{rpm}$.

like mass upon water absorption which was smooth and devoid of grittiness [5].

The PO husk is bulky in nature and has poor compressibility, and ODTs were expected to be soft. But ODTs had good mechanical strength, and poor compressibility of the PO husk was compensated by other excipients. The highest concentration of the PO husk $(15 \% w / w)$ was in formulation F-7, and it had a good mechanical strength which proved that it had no adverse effect on the mechanical strength of ODTs. All the formulations showed rapid disintegration in the oral cavity. A direct correlation was observed between the in vitro disintegration time and the oral disintegration time, as shown in Figure 5. Decrease in the disintegration time was accompanied by a decrease in the oral disintegration time and vice versa. The PO husk showed a concentrationdependent decrease in the disintegration time. Furthermore, addition of other disintegrants resulted in a synergistic effect. The main disadvantage of available synthetic disintegrants is the low mechanical strength of tablets. It has been reported that use of a large quantity of super disintegrants results in tablets with poor friability. Poor friability is more pronounced in the case of ODTs which are compressed at a relatively lower compression force. The PO husk overcomes the problem by increasing the mechanical strength through the formation of a strong linkage with other particles which strengthens the ODTs. Furthermore, it absorbs water rapidly 
due to its high swelling index, resulting in rapid disintegration. All the formulations containing the PO husk up to $10 \%$ (F-2 to F-5) showed similar drug release profiles, and differences were made on the basis of burst release, i.e., drug release during the initial 15 minutes. The PO husk showed a concentration-dependent burst release of the drug and an increase in the concentration of the PO husk resulted in a higher drug release. Drug release from ODTs can be correlated with their disintegration time. All the formulations with a smaller disintegration time showed a higher burst release, as shown in Figure 6. It may be due to the quick exposure of the drug to dissolution media upon rapid disintegration which resulted in better dissolution. Rapid disintegration and sink condition are responsible for burst release from ODTs. Formulation F-1 was used as a control and was devoid of the PO husk and other disintegrants. It showed the largest disintegration time $(194 \mathrm{sec})$ and the lowest drug release $(75.81 \pm 1.26 \%)$ during the initial $15 \mathrm{~min}$. Inclusion of a higher concentration of PO husk $(15 \% w / w)$ resulted in a slower drug release which may be due to its gelling action. At a higher concentration, the PO husk forms a gel-like structure which decreased the drug release. However, the resultant gel was not strong enough to retard the drug release for a longer period of time. So the PO husk can be used as a pharmaceutical excipient (disintegrant and glidant), without compromising the mechanical strength of tablets.

\section{Conclusions}

It was concluded that the PO husk could be used as a disintegrant in the formulation of ODTs.

\section{Data Availability}

Upon request data could be requested from the shared corresponding author Dr. Amjad Khan dr.amjad@kust.edu.pk.

\section{Conflicts of Interest}

The authors declare that they have no financial or other conflicts of interest in relation to this research and its publication.

\section{Acknowledgments}

The authors highly acknowledge Dr. Asad MHHB (CUI Abbottabad, Pakistan) for his sincere efforts to publish this work.

\section{References}

[1] H. Majmudar, V. Mourya, S. Devdhe, and R. Chandak, "Pharmaceutical applications of ispaghula husk: mucilage," International Journal of Pharmacy and Pharmaceutical Sciences, vol. 18, no. 1, pp. 49-55, 2013.

[2] L. K. Jain, "Economic and gap analysis in isabgol cultivation through frontline demonstrations in Western Rajasthan," International Journal of Agricultural Extension, vol. 2, no. 2, pp. 109-114, 2014.
[3] P. Pagaria and S. L. Kantwa, "Role of front line demonstration on transfer of isabgol production technology in Barmer district of Rajasthan," AGRICULTURE UPDATE, vol. 9, no. 3, pp. 292-295, 2014.

[4] V. Van-Craeyveld, J. A. Delcour, and C. M. Courtin, "Extractability and chemical and enzymic degradation of psyllium (Plantago ovata Forsk) seed husk arabinoxylans," Food Chemistry, vol. 112, no. 4, pp. 812-819, 2009.

[5] A. Raissi, M. Galavi, M. Zafaraneieh, M. Soluki, and S. Roholla, "Biochemical change of seed and yield of Isapgol under biofertilizer, organic manure and chemical fertilizer," Bulletin of Environment, Pharmacology and Life Sciences, vol. 2, no. 6, pp. 112-117, 2013.

[6] G. Deokar, S. Kshirsagar, P. Deore, and H. Kakulte, "Pharmaceutical benefits of P. ovata (isabgol seed): a review," Pharmaceutical and Biological Evaluations, vol. 3, no. 1, pp. 32-41, 2016.

[7] S. Kumari, S. Sharma, and B. Dutt, "Traditional uses of common herbs of Baijnath region of Himanchal Pradesh India," World Journal of Pharmacy and Pharmaceutical Sciences, vol. 4, no. 10, pp. 916-922, 2015.

[8] B. M. Mithal and J. L. Kasid, "Hydrophile-lipophile balance values of Plantago ovata seed husk and water soluble fraction of its mucilage," Indian Journal of Pharmacology, vol. 27, pp. 116-118, 1965.

[9] B. M. Mithal and V. D. Gupta, "Suspending properties of Plantago ovata seed husk (ispaghula) mucilage," Indian Journal of Pharmacology, vol. 27, pp. 331-334, 1965.

[10] B. M. Mithal and B. R. Bhutiani, "Binding properties of Plantago ovata (ispaghula) seed husk mucilage," Indian Journal of Pharmacology, vol. 31, pp. 55-57, 1969.

[11] P. C. Khasgiwal and B. M. Mithal, "Derivatives of Plantago ovata seeds husk gum. Part I. Carboxyl derivatives," Indian Journal of Pharmacology, vol. 37, no. 3, pp. 53-55, 1975.

[12] A. K. Jain and B. M. Mithal, "Derivatives of Plantago ovata seed husk gum. Part II. Methoxy derivative," Indian Journal of Pharmacology, vol. 38, no. 1, pp. 15-17, 1976.

[13] G. L. Sameer, Y. Yi-Ying, and A. K. Banga, "Effects of disintegration promoting agent, lubricants and moisture treatment on optimized fast disintegrating tablets," International Journal of Pharmaceutics, vol. 365, no. 1-2, pp. 4-11, 2009.

[14] G. Abdelbary, C. Eouani, P. Prinderre, J. Joachim, J. Reynier, and P. Piccerelle, "Determination of the in vitro disintegration profile of rapidly disintegrating tablets and correlation with oral disintegration," International Journal of Pharmaceutics, vol. 292, no. 1-2, pp. 29-41, 2005.

[15] N. Zhao and L. L. Augsburger, "Functionality comparison of 3 classes of superdisintegrants in promoting aspirin tablet disintegration and dissolution," AAPS PharmSciTech, vol. 6, no. 4, pp. E634-E640, 2005.

[16] D. Silvers, M. Kipnes, V. Broadstone et al., "Domperidone in the management of symptoms of diabetic gastroparesis: efficacy, tolerability, and quality-of-life outcomes in a multicenter controlled trial," Clinical Therapeutics, vol. 20, no. 3, pp. 438453, 1998.

[17] The United States pharmacopeia and national formulary USP 38-NF 33, The United States Pharmacopeial Convention, Inc, Rockville, MD, 2015.

[18] British Pharmacopoeia, The Stationery Office, London, 2012.

[19] A. Khan, Z. Iqbal, M. Ibrahim, F. Nasir, and Z. Ullah, "Prediction of the effect of taste masking on disintegration behavior, mechanical strength and rheological characteristics of highly 
water soluble drug (itopride $\mathrm{HCl}$ ); an application of SeDeMODT expert system," Powder Technology, vol. 284, pp. 411417, 2015.

[20] S. Kala, "Effect of $\mathrm{NaCl}$ stress on chlorophyll content of isabgol (Plantago ovata Forsk) genotypes," Research on Crops, vol. 18, no. 2, p. 332, 2017.

[21] A. Khan, Z. Iqbal, A. Khan, and I. Khan, "Formulation and evaluation of taste masked orally disintegrating tablets of itopride $\mathrm{HCl}$ using hydrophillic polymers as drug carrier," Latin American Journal of Pharmacy, vol. 34, no. 7, pp. 1364-1372, 2015. 